\title{
Finite Element Analysis of Stress Distribution in Normal and Osteoporosis Pelvis Models
}

\author{
BOGDAN VELICEASA ${ }^{1}$, OVIDIU ALEXA ${ }^{1 *}$, PAUL DAN SIRBU ${ }^{1 *}$, ALEXANDRU FILIP $^{1 *}$, EDWARD RAKOSI ${ }^{2}$, \\ OANA VIOLA BADULESCU ${ }^{3}$ \\ ${ }^{1}$ Grigore T. Popa University of Medicine and Pharmacy, Faculty of Medicine, Department of Orthopedics and Traumatology Surgical Sciences (II), \\ 16 Universitatii Str., 700115, Iasi, Romania \\ ${ }^{2}$ Gheorghe Asachi Technical University, Faculty of Mechanical Engineering, Department of Mechanical and Automotive Engineering ,43 B Profesor \\ Dimitrie Mangeron Blvd., 700050, Iasi, Romania \\ ${ }^{3}$ Grigore T. Popa University of Medicine and Pharmacy, Faculty of Medicine, Department of Pathophysiology, Morfo-Functional Sciences (II), \\ 16 Universitatii Str., 700115, Iasi, Romania
}

Finite element analysis is the most commonly used methods in orthopedic biomechanical research. The study aims at improving the common understanding of the behavior of the pelvis and the biomechanics of the pelvic ring in a healthy and osteoporosis configuration. We performed a finite element analysis using the ANSYS program. The study mainly focused on bones and the joints and the complex modelling of the ligaments was ignored. The results of our study showed that the stress distribution of the pelvis with osteoporosis was changed compared with normal pelvis. In addition to, in the healthy bone, where the maximum stress values are concentrated around the obturator foramen (anterior arch of the pelvic ring), in the osteoporotic bone, the maximum stress also appear at the posterior arch of the pelvic ring (especially in the sacrum).

Keywords: osteoporosis, fragility fractures of the pelvis, stress distribution

Osteoporosis is a consequence of ageing and is recognized as serious public health problem. The consequence of osteoporosis is the high risk of fracture. The main risk factors for fracture $(R R \geq 2)$ are: age, bone mineral density, history of fragility fracture history, family history of fragility fracture, menopause under 45 years, the treatment with glucocorticoids, prolonged immobilization, anorexia, susceptibility to failure, malabsorption, chronic renal failure, heart transplantation [1$3]$. Among the moderate risk factors $(1<\mathrm{RR}<2)$ literature mentioned: rheumatoid arthritis, Bechterew's disease, treatment with anticonvulsant, a low calcium, diabetes insipidus, estrogen deficiency, primary hyperparathyroidism, hyperthyroidism, smoking, excessive alcohol [4].Some authors suggest the homocysteine as a newly recognized risk factor for the osteoporotic fractures, but the opinions are controversial [5-8].

Osteoporotic fractures are encountered especially in the spine, hip (14\%) of the distal radius (18\%) and the proximal humerus, but they may occur at other sites such as the pelvis (7\%), ribs, femur, tibia [9-11]. The Fragility Fractures of the Pelvis (FFP) are different in terms of traumatic mechanism, morphology and treatment. They occur due to low energy trauma. Most patients suffer FFP after a minor injury, usually by dropping from their own height or from a sitting position. The main symptom is pain that occurs in the pubic region or groin and back to the sacrum or sacroiliac joint [12]. Functional limitation is different [13]. Some patients can travel short distances aided by axillary crutches or walker, in other cases occurring total functional failure. Hemodynamic instability is very rare [14] with no concomitant injuries. Diagnosis and evaluation of FFP involves: a) history b) physical examination c) X-ray that highlights fractures in the branches, for the case of injuries at the back that are hard to see and can be omitted d) bone scintigraphy e) computed tomography (CT) which highlights the degree of extension of the lesion and f) nuclear magnetic resonance (NMR) [15,16]. Humphrey et al. [17] believe that the vast number of patients with osteoporosis, pelvic pain (caused by injury or not) is a serious matter and investigation by advanced imaging techniques is essential in the diagnosis of fragility fracture. Soles et.al [18] conclude that slight back pain and pelvis after fall or in the absence of trauma is considered a major index of suspicion ("high index of suspicion") for the fragility fracture in the elderly. To prevent bone loss some studies support the concept of using nitric oxide donors which can have anti-inflammatory effects [19].

Lately, digital models based on finite element analysis are preferred to highlight bone stress or strain due to bone-implant interaction.

The material model used is based on a constant Young's modulus or apparent bone density obtained from computed tomography data. The development of osteoporosis significantly affects the decrease of the mechanical parameters of bone

*email: ovidiu_alexa@yahoo.com ; pdsirbu@yahoo.com; alexandru.filip@ymail.com 
structures. Dickenson et al. [20] reported that the average Young's modulus for normal bone tissue has value of $16.586 \mathrm{GPa}$ (range 67-86 years) and for an osteoporotic bone it is much smaller, with a value of 11.554 GPa (range 67-91 years).

The study aims at improving the common understanding of the behavior of the pelvis and the biomechanics of the pelvic ring in a healthy and osteoporosis configuration.

\section{Experimental part}

We performed a finite element analysis using the ANSYS program. For this study, we simulated a person $170 \mathrm{~cm}$ height and $85 \mathrm{~kg}$ weight. The weight that acts on the pelvis, when the person is about to sit in the chair, is the opposite of the weight represented by the weight of the body from the middle upwards, including the upper limbs, neck and head. The study mainly focused on bones and the joints and the complex modelling of the ligaments was ignored. Mechanical properties for the normal bone and osteoporotic bone, having a linear isotropic elastic behavior (Young's modulus E, Bone density $\rho$, Breaking point $\sigma$, Poisson ratio $v$ ) were defined as given in Table 1.

Table 1

MECHANICAL PROPERTIES OF FINITE ELEMENT MODEL

\begin{tabular}{|c|c|c|}
\hline Properties & Normal bone & Bone with osteoporosis \\
\hline Young's modulus & $\boldsymbol{E}=18,9 \cdot 10^{3}[\mathrm{MPa}]$ & $\boldsymbol{E}=7,9 \cdot 10^{3}[\mathrm{MPa}]$ \\
\hline Mass density & $\boldsymbol{\rho}=2 \cdot 10^{3}\left[\mathrm{~kg} / \mathrm{m}^{3}\right]$ & $\boldsymbol{\rho}=1,2 \cdot 10^{3}\left[\mathrm{~kg} / \mathrm{m}^{3}\right]$ \\
\hline Breaking limit & $\boldsymbol{\sigma}=121[\mathrm{MPa}]$ & $\boldsymbol{\sigma}=80[\mathrm{MPa}]$ \\
\hline Poisson ratio & $\boldsymbol{v}=0,3$ & $\boldsymbol{v}=0,3$ \\
\hline
\end{tabular}

In the figure 1 is show the situation transposed from reality, in which the number 1 represents the mass of the body acting on the falling pelvis. The number 2 is represented by the pelvic assembly, and the number 3 represents the surface with which the pelvis comes into contact. The height from which the pelvis is dropped is considered $1 \mathrm{~m}$.

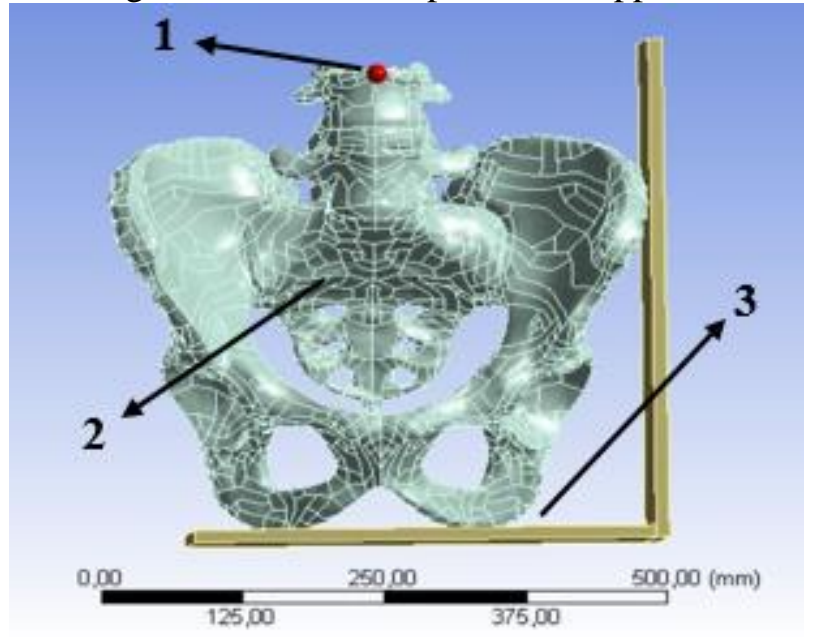

Fig. 1.Model for finite element analysis

\section{Results and discussions}

Finite element analysis is the most commonly used methods in orthopedic biomechanical research.

In first model we attributed to the pelvic assembly the mechanical properties of the normal pelvis and subjected it to a fall from $1 \mathrm{~m}$ in height. The weight of the body and that of the upper limbs of the pedestrian acted on the pelvis, which we approximated would be equal to $70 \mathrm{~kg}$.

Stress distribution in a finite element intact pelvic model with normal bone is showed in the figure 2 and figure 3. 


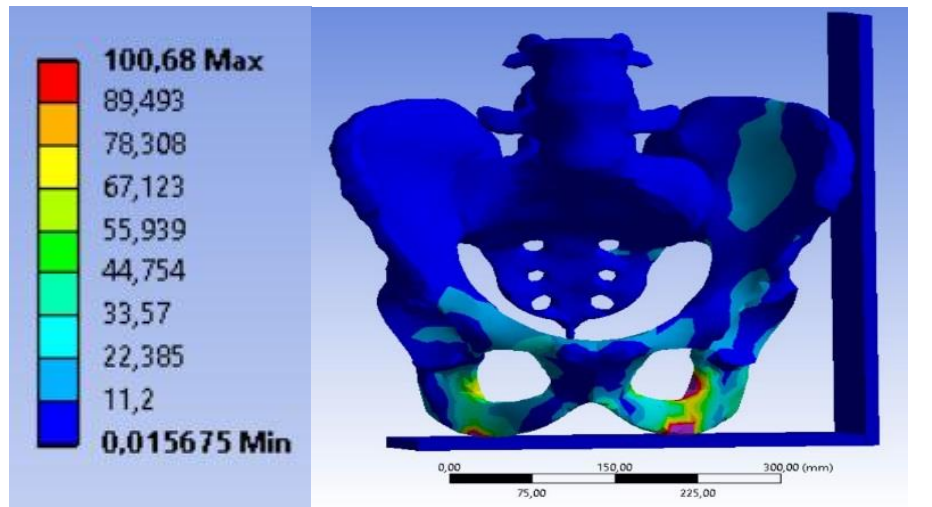

Fig. 2. Frontal view of Von Mises stresses distribution in normal pelvis model

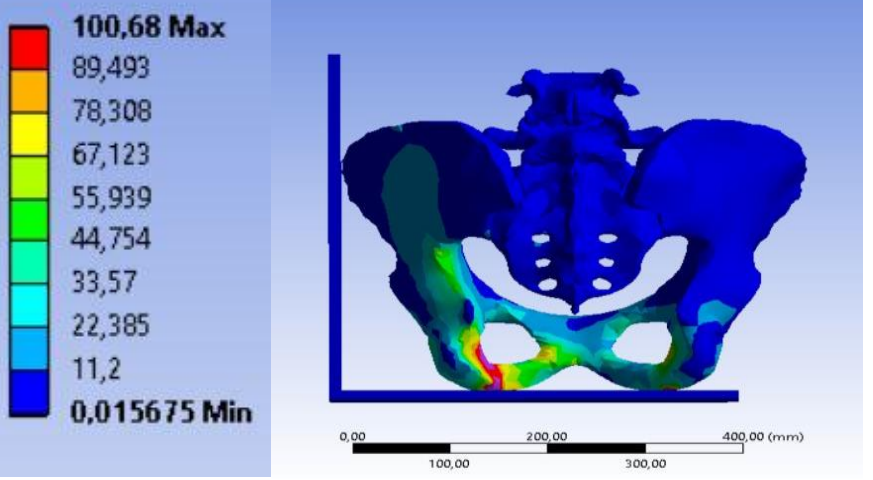

Fig. 3. Posterior view of Von Mises stresses distribution in the normal pelvis

In the finite element analysis the scale of values of Von Mises stresses, presented in the images in figure 2 and figure 3 , contains values between $0.01[\mathrm{MPa}]$, and 100.68 [MPa ].

The stress concentrated mainly on the origin of the ascending branch of the ischium, where the maximum stress value $100 \mathrm{MPa}$ was localized.

Distribution of von Mises stress in the intact pelvic model with osteoporosis is presented in figure 4 and figure 5.

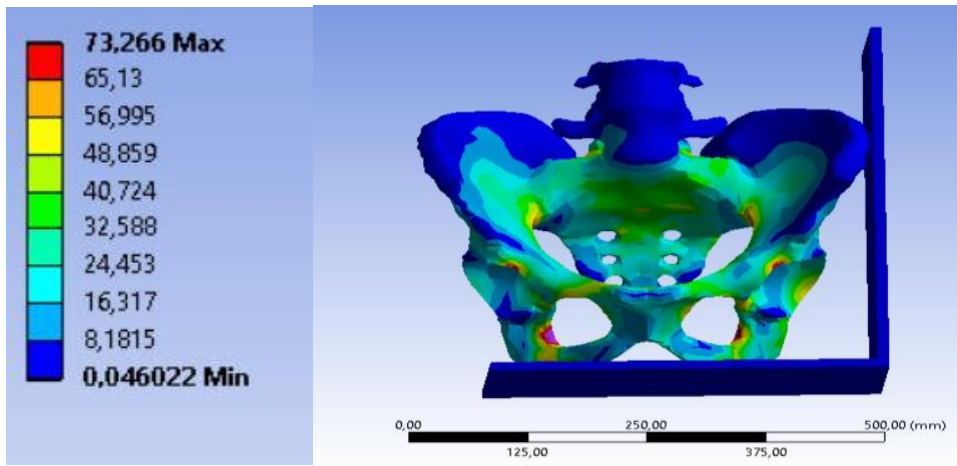

Fig. 4. Frontal view of Von Mises stresses distribution in the pelvis with osteoporosis

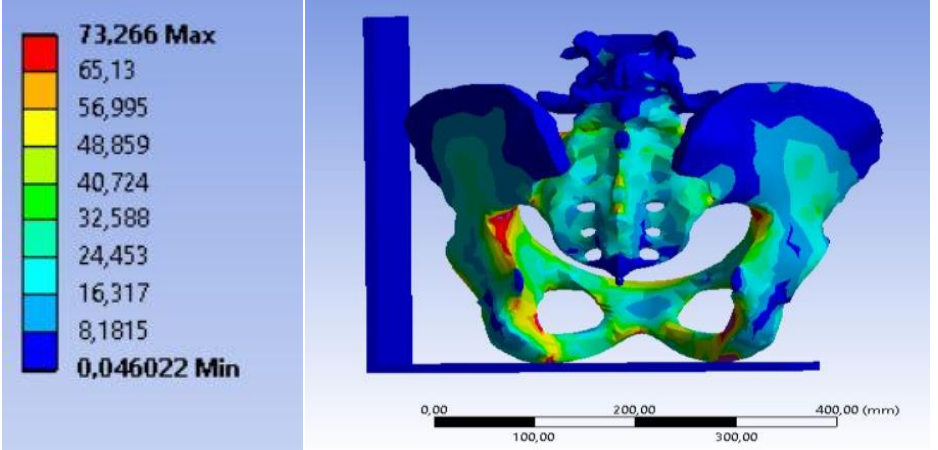

Fig. 5. Posterior views of Von Mises stresses distribution in the pelvis with osteoporosis 
In this model we attributed to the pelvic assembly the mechanical properties of the osteoporotic bone and subjected it to a fall from $1 \mathrm{~m}$ in height.

In the finite element analysis the scale of values of Von Mises stresses, presented in the images in figure 4 and figure 5, contains values between 0.04 [MPa], the value represented by the blue color being the lower limit, and 73.26 [MPa ], the value represented by the red color being the upper limit.

Comparing the maximum value of Von Mises stresses resulting from the finite element analysis with the breaking resistance of the osteoporotic bone, we observe that the values of the two are close. In this case in the areas where the equivalent tension is maximum we can have fractures of small size of the bone.

It is difficult to construct a 3-D (finite element) finite model for the human pelvis, because it has a complex structure including muscles and ligaments [21].

Ravera et al. [22] reported that sensitivity values for the models suggests that finite element predicted stress were not very sensitive to changes in the material properties assumed in their model for cartilage and bone.

Ricci et al. [23] investigated the loads transmission within the pelvic ring under physiological loadings of the gait and concluded that a superior ramus fracture altered anteriorly and posteriorly the load distribution.

In the finite element analysis in which the healthy pelvis is falling from about $1 \mathrm{~m}$ high we can conclude that fracture lines occur in the ischium or the ascending branch of the ischium. In the osteoporotic bone fractures occur at the level of the ischium, the ilio-pubic branches and also at the level of the sacrum.

\section{Conclusions}

The results of our finite element analysis showed that the stress distribution of the pelvis with osteoporosis was changed compared with normal pelvis. Beside that in the healthy bone, where the maximum stress is concentrated around the obturator foramen (anterior arch of the pelvic ring), in the osteoporotic bone, the maximum stress appear also at the posterior arch of the pelvic ring (especially in the sacrum).

\section{References}

1.BLIUC, D., NGUYEN, N.D., NGUYEN, T.V., EISMAN, J.A., CENTER, J.R., Compound risk of high mortality following osteoporotic fracture and re-fracture in elderly women and men, J Bone Miner Res.,28,nr.11, 2013, p.2317-24.

2. PISANI, P., RENNA, M. D., CONVERSANO, F., CASCIARO, E., DI PAOLA, M., QUARTA, E., MURATORE, M.,CASCIARO, S., Major osteoporotic fragility fractures: Risk factor updates and societal impactWorld, J Orthop., 7, nr.3,2016,p.171-181.

3.ADAMS, A.L., ADAMS, J.L., RAEBEL, M.A., TANG, B.T., KUNTZ, J.L., VIJAYADEVA, V., MCGLYNN, E.A., GOZANSKY, W.S., Bisphosphonate Drug Holiday and Fracture Risk, J Patient Cent Res Rev, 2,nr.2,2015,p.101.

4.SELLMEYER, D., CIVITELLI, R., HOFBAUER, L.C., KHOSLA, S., LECKA-CZERNIK, B., SCHWARTZ, A.V., Skeletal Metabolism, Fracture Risk, and Fracture Outcomes in Type 1 and Type 2 Diabetes, Diabetes,65,nr.7, 2016,p.1757-1766.

5.ZHU, Y., SHEN, J., CHENG, Q., FAN, Y., LIN, W., Plasma homocysteine level is a risk factor for osteoporotic fractures in elderly patients, Clinical interventions in aging, 11, 2016, p. 1117.

6.FILIP, C., ALBU, E., LUPASCU, D., FILIP, N., The influence of a new rutin derivative in an experimental model of induced hyperhomocysteinemia in rats. Farmacia, 2017, 65, nr.4, p.596-599.

7.FILIP, C., ALBU, E., ZAMOSTEANU, N., IRINA, M., SILION, M., JERCA, L., COSTEL, M., Hyperhomocysteinemia's effect on antioxidant capacity in rats, Open Medicine, 5,nr.5,2010,p. 620-626.

8.ALBU, E., LUPASCU, D., FILIP, C., JABA, I.M., ZAMOSTEANU, N., The influence of a new Rutin derivative on homocysteine, cholesterol and total antioxidative status in experimental diabetes in rats, Farmacia, 61, nr.6, 2013, p.1167.

9.HOCH, A., PIEROH, P., DEHGHANI, F., JOTEN, C., BOHME, J., An Atraumatic Symphysiolysis with a Unilateral Injured Sacroiliac Joint in a Patient with Cushing's Disease: A Loss of Pelvic Stability Related to Ligamentous Insufficiency?, Case Rep Orthop., $2016,2016$.

10.NELLANS, K. W., KOWALSKI, E., CHUNG, K. C., The epidemiology of distal radius fractures, Hand clinics, 28,nr.2,2012,p.113-125.

11.SCHNELL, AMANDA D., CURTIS, JEFFREY, R., SAAG, KENNETH, G., Importance of Recent Fracture as Predictor of Imminent Fracture Risk. Current osteoporosis reports, 16, nr. 6, 2018, p. 738-745.

12.FILIP, A., VELICEASA, B., PUHA, B., FILIP, C., POPESCU, D., ALEXA, O., Bisphosphonates Influence and Pain Assessment in Mobilization of Patients with Fragility Fracture of the Pelvis, Rev. Chim. (Bucharest), 70, no.3, 2019,p. 1094-1097.

13.BADULESCU, O. V., CIOCOIU, M., FILIP, N., VERINGA, V., The Efficiency of Substitutive Treatment with Moroctocog Alfa in Managing Hemostasis in Patients with Hemophilia A Without Inhibitors With Total Knee Arthroplasties. REVISTA DE CHIMIE, 69, nr.12, 2018, p.3702.

14.BAYLEY, E., SRINIVAS, S., BOSZCZYK, B. M., Clincal outcomes of sacroplasty in sacral insufficiency fractures: a review of the literature, Eur. Spine J., 18,2009, p. 1266-1271.

15.BORGGREFE, J., DE BUHR, T., SHRESTHA, S., MARSHALL, L. M., ORWOLL, E., PETERS, K., BLACK, D. M., GLÜER, C. C., Association of 3D Geometric Measures Derived From Quantitative Computed Tomography With Hip Fracture Risk in Older Men, J Bone Miner Res, 31,nr.8, 2016,p. 1550-1558.

16.LYDERS, E. M., WHITLOW, C. T., BAKER, M. D., MORRIS, P. P., Imaging and treatment of sacral insufficiency fractures, AJNR Am J Neuroradiol, 31 ,nr.2,2010,p.201.

17.HUMPHREY, C.A., MACEROLI, M.A., Fragility fractures requiring special consideration: pelvic insufficiency fractures, Clin Geriatr Med., 30,nr.2,2014,p.373-86.

18.SOLES, G. L., FERGUSON, T. A., Fragility fractures of the pelvis. Current reviews in musculoskeletal medicine, 5,nr.3,2012,p. 222-228. 
19.BUCA, B.R., TARTAU, L.M., REZUS, C., FILIP, C., PINZARIU, A.C., REZUS, E., POPA, G.E., PANAINTE, A., LUPUSORU, C.E., BOGDAN, M., PAVEL, L., The Effects of Two Nitric Oxide Donors in Acute Inflammation in Rats, Rev. Chim. (Bucharest), 69, no.10, 2018, p.2899.

20.DICKENSON R.P., HUTTON W.C., STOTT J.R.R., The mechanical properties of bone in osteoporosis, J. Bone Joint Surg., 63, 1981, p.233238.

21.SHI, D., WANG, F., WANG, D., LI, X., WANG, Q. 3-D finite element analysis of the influence of synovial condition in sacroiliac joint on the load transmission in human pelvic system, Medical engineering \& physics, 36,nr.6, 2014,p.745-753.

22.RAVERA, E. P., CRESPO, M. J., GUARNIERI, F. A., \& BRAIDOT, A. A., Stress in human pelvis throughout the gait cycle: development, evaluation and sensitivity studies of a finite element model. In VI Latin American Congress on Biomedical Engineering CLAIB 2014, Paraná, Argentina 29, 30 \& 31 October 2014 (pp. 246-249). Springer, Cham,2015,p. 246-249.

23.RICCI, P. L., MAAS, S., KELM, J., GERICH, T.,Finite element analysis of the pelvis including gait muscle forces: an investigation into the effect of rami fractures on load transmission, Journal of experimental orthopaedics, 5,nr.1,2018,p. 33

Manuscript recveived: 31.10 .2019 